\title{
Pharmacoepidemiology and clinical characteristics of medication-related osteonecrosis of the jaw
}

\author{
Hyo-Jeong Son, Jin-Woo Kim (D) and Sun-Jong Kim ${ }^{*}$
}

\begin{abstract}
Background: The aim of this study was to investigate clinical and pharmacoepidemiologic characteristics of medicationrelated osteonecrosis of the jaw.

Methods: The study population is comprised of 86patients who were diagnosed with ONJ at Ewha Womans University Mokdong Hospital from 2008 to 2015. Factors for epidemiologic evaluation were gender, age, location of lesion, and clinical history. The types of bisphosphonates, duration of intake, and the amount of accumulated dose were evaluated for therapeutic response. Clinical symptoms and radiographic images were utilized for the assessment of prognosis.

Results: Among the 86 patients, five were male, whereas 81 were female with mean age of 73.98 (range 45-97). Location of the lesion was in the mandible for 58 patients and maxilla in 25 patients. Three patients had both mandible and maxilla affected. This shows that the mandible is more prone to the formation of ONJ lesions compared to the maxilla. ONJ occurred in 38 cases after extraction, nine cases after implant surgery, six cases were denture use, and spontaneously in 33 cases. Seventy-six patients were taking other drugs aside from drugs indicated for osteoporosis. Most of these patients were diagnosed as osteoporosis, rheumatic arthritis, multiple myeloma, or had a history of cancer therapy. Higher weighted total accumulation doses were significantly associated with poorer prognosis $(P<0.05)$.
\end{abstract}

Conclusion: Dose, duration, route, and relative potency of bisphosphonates are significantly associated with treatment prognosis of osteonecrosis of the jaw.

Keywords: MRONJ, Weight dose deposited, Bisphosphonate, Pharmacoepidemiology

\section{Background}

In 2003, the first cases of what has become known as medication-related osteonecrosis of the jaw (MRONJ) were reported by Marx [1]. Initially, osteonecrosis was reported only after treatment with bisphosphonates and referred to as bisphosphonate-related osteonecrosis of the jaw (BRONJ) [2]. Since 2014, the term MRONJ was recommended by the American Association of Oral and Maxillofacial Surgeons (AAOMS) [3]. The change is justified to accommodate the growing number of cases of osteonecrosis that are associated with other antiresorptive and antiangiogenic treatments in patients who have not used bisphosphonates previously [4-7].

\footnotetext{
*Correspondence: mk@swdh.co.kr; mk@swdh.co.kr

Department of Oral and Maxillofacial Surgery, School of Medicine, Ewha Womans University, Anyangcheon-ro 1071, Yangcheon-gu, Seoul 158-710, South Korea
}

MRONJ is an uncommon condition that can occur after exposure to agents but it is now established as clinically significant, which may cause pain and debilitating conditions in patients, significantly affecting their quality of life [8].

MRONJ is found to be more prevalent in patients with high cumulative doses of bisphosphonates or other agents than in those with lower doses $[9,10]$ and high incidence of MRONJ has been reported when the agents are administered intravenously (IV) than taken intraorally [11-17]. The mechanism of action of bisphosphonates is not yet well understood, but it essentially involves a powerful inhibition of bone resorption as a result of the reduction of osteoclast activity [18].

The risk factors for MRONJ are classified as medicationrelated factors, local factors, demographic factors, systemic factors, other medication factors [19-26]. 
This study aims to investigate the pharmacoepidemiology and clinical features of MRONJ.

\section{Methods}

This study was a retrospective study, analyzing the archived materials. All patients involved in the study took panoramic $x$-rays to rule out the other etiologies and biopsy was also performed. Patients who were diagnosed with MRONJ at the department of Oral and Maxillofacial Surgery in Ewha Womans University Mokdong Hospital from 2008 to 2015 were included in this study.

\section{Basic demographics of the samples}

Factors for epidemiologic evaluation were gender, age, location of lesion, and clinical history (potential local risk event of MRONJ and underlying bone disease). The information on comorbidity is obtained from the medical records or through the interviews of the patients. The types of bisphosphonates, duration of intake, route of administration, and the amount of accumulated dose were evaluated. Clinical symptoms and radiographic images were used to assess the prognosis for therapeutic response.

\section{MRONJ staging and treatment respond}

The staging system of AAOMS, which may reflect the disease manifestations and help the appropriate assessments on patients [8], we followed MRONJ staging system and treatment assessments by AAOMS recommendations. An initial stage 0 is described, in which there is no clinical evidence of necrotic bone, and yet patients present with non-specific symptom or clinical and radiographic findings [3]. All patients were followed up for 12 months. Treatment response was divided into complete, delayed, and none. 'Complete' means completely healed state, while 'delayed' means down-staged but not completely healed state and 'none' being the same staging state even after the treatment for MRONJ.

\section{Bisphosphonates}

The following variables were analyzed for the bisphosphonates: the average administered dose in milligrams (mg), average dose deposited in bone tissue in milligrams (mg), and weighting dose/potency according to the bisphosphonate used. The following equation was applied to determine the average milligrams $(\mathrm{mg})$ deposited in bone tissue.

Average dose $(\mathrm{mg})$ deposited in bone $=$ average dose $(\mathrm{mg})$ administered $\times$ deposit rate to the bone/100 (the percentage of the deposit of bisphosphonates is $1 \%$ when taken intraorally and $70 \%$ when administered intravenously) [27].

Then, the weight of the dose deposited in the bone tissue was adjusted to the relative potency [28] (Table 2) of each bisphosphonate with the following formula [29]:
Weight dose deposited $=$ average deposited in bone $\times$ relative potency.

\section{Statistical analysis}

The statistical analysis was performed using Microsoft Excel and Statistical Package for the Social Sciences (SPSS) ver. 17.0. ANCOVA/Ordinal logistic regression was used to evaluate the correlation between actual weight dose deposited according to the MRONJ Clinical Staging, weight dose deposited according to the treatment response, and factors of age, sex, indication, and medical comorbidities were adjusted. Values of the weight dose deposited were applied logarithm for normal distribution.

\section{Results}

The majority of subjects were females with only $5.8 \%$ being males. A total of $86 \mathrm{MRONJ}$ patients with mean age of 73.98 years (range, 45-97) were evaluated. The therapeutic indication for bisphosphonate (BP) was osteoporosis in $76(88.4 \%)$ cases, bone metastasis in six (9.6\%) cases, and multiple myeloma in four $(6.4 \%)$ cases.

The staging was performed using AAOMS criteria. Sixty of the patients $(69.8 \%)$ were in stage 2 , while 15 patients (17.4\%) in stage 3 and 11 patients $(12.8 \%)$ in stage 1. Fifty-eight patients (67.4\%) presented osteonecrosis in the mandible, while 25 patients $(29.1 \%)$ in the maxilla, and three patients (3.5\%) in both.

It is found that 38 patients (44.2\%) recently had dental extractions, nine (10.5\%) implant surgery, and six $(7.5 \%)$ use dentures. In 33 patients (38.4\%), osteonecrosis was apparently spontaneous, without any noticeable or obvious factor.

Still, among these patients, 52 patients were found to have hypertension (HTN), 22 patients to have diabetes mellitus (DM), and 15 patients to have cardiovascular disease (CVD). Also, 15 patients have had steroid therapy and 14 patients had radiotherapy but not in head and neck region. Seven patients had mental disorders and five patients had history of thyroid disease. Four patients had asthma and two patients had endstage renal disease (ESRD). One patient was found to have liver disease.

Thirty-two patients have been treated with BPs for more than 5 years. Twelve patients were exposed to BPs for between 4 and 5 years while three patients for 3-4 years, 19 patients for 2-3 years, and 14 patients for 1-2 years. Patients who had exposure under 1 year were six.

Seventy patients had oral BPs, while ten patients were administered intravenously. Six patients had both oral and intravenous BPs. Forty-four patients took alendronate, while 18 took Ibandronate, 15 risedronate, three pamidronate, and six zoledronate. The clinical characteristics of 
the patients who were diagnosed with MRONJ mentioned earlier are grouped (Table 1).

Following up the 86 patients, 31 patients were found to be completely healed, while 39 patients were downstaged but not completely healed and 16 patients had no changes in staging.

Table 1 Clinical characteristics of the patients who were diagnosed with MRONJ

\begin{tabular}{|c|c|c|}
\hline Variable & & Number $[n=86](\%)$ \\
\hline \multirow[t]{3}{*}{ Underlying bone disease } & Osteoporosis & 76 (88.4\%) \\
\hline & Bone metastasis & $6(9.6 \%)$ \\
\hline & Multiple myeloma & $4(6.4 \%)$ \\
\hline \multirow[t]{3}{*}{ MRONJ stage at diagnosis } & Stage 1 & $11(12.8 \%)$ \\
\hline & Stage 2 & $60(69.8 \%)$ \\
\hline & Stage 3 & 15 (17.4\%) \\
\hline \multirow[t]{3}{*}{ MRONJ location } & Maxilla & $25(29.1 \%)$ \\
\hline & Mandible & $58(67.4 \%)$ \\
\hline & Both & $3(3.5 \%)$ \\
\hline \multirow[t]{4}{*}{ Potential risk events } & Spontaneous & $33(38.4 \%)$ \\
\hline & Extraction & $38(44.2 \%)$ \\
\hline & Implant surgery & $9(10.5 \%)$ \\
\hline & Denture use & $6(7.0 \%)$ \\
\hline \multirow[t]{10}{*}{ Medical comorbidities } & HTN & 52 \\
\hline & CVD & 15 \\
\hline & $\mathrm{DM}$ & 22 \\
\hline & Asthma & 4 \\
\hline & RA & 14 \\
\hline & Steroid & 15 \\
\hline & Thyroid & 5 \\
\hline & Mental & 7 \\
\hline & ESRD & 2 \\
\hline & Liver & 1 \\
\hline \multirow[t]{6}{*}{ Duration of BPs exposure } & 1 year & $6(7.0 \%)$ \\
\hline & $1 \sim 2$ year & $14(16.3 \%)$ \\
\hline & $2 \sim 3$ year & 19 (22.1\%) \\
\hline & $3 \sim 4$ year & $3(3.5 \%)$ \\
\hline & $4 \sim 5$ year & $12(13.9 \%)$ \\
\hline & $>5$ year & $32(37.2 \%)$ \\
\hline \multirow[t]{5}{*}{ Types of BPs } & Alendronate & $44(51.2 \%)$ \\
\hline & Ibandronate & $18(20.9 \%)$ \\
\hline & Risedronate & 15 (17.4\%) \\
\hline & Pamidronate & $3(3.5 \%)$ \\
\hline & Zoledronate & $6(7.0 \%)$ \\
\hline \multirow[t]{3}{*}{ Route of administration } & $\mathrm{PO}$ & $70(81.4 \%)$ \\
\hline & IV & $10(11.6 \%)$ \\
\hline & Both & $6(7.0 \%)$ \\
\hline
\end{tabular}

Since every underlying disease was counted in each patients. Medical comorbidities was over than 86

\section{Bisphosphonates}

Despite its greater dosage, relatively lower potency, and reduced volume of absorption, the average dose of bisphosphonates taken intraorally was higher both in the case of using pamidronate $(142,750 \mathrm{mg})$ and alendronate $(17,633 \mathrm{mg})$ and using ibandronate $(51.43 \mathrm{mg})$ and zoledronate $(62.67 \mathrm{mg})$, compared to the mean doses when administered intravenously. After the adjustment of average administered dose and dose deposited in the bone tissue, a smaller deposit was found in oral formulations and among the drugs; the pamidronate presented the highest deposits in the bone tissue. Finally, by weighing the mean dose deposited in bone tissue with the relative potency referenced to each bisphosphonate, among them highest weight dose deposited/1000 is zoledronate (4386.90) and then, risendronate (1972.25) intravenously (Table 2).

\section{Weight dose deposited according to MRONJ clinical stage and treatment response}

Values of actual weight dose deposited/1000 was calculated and averaged for each stage and stage I was 195.15 (SD260.97), stage 2 was 589.82 (SD746.3), and stage 3 was 4379.89 (SD7317.72). Calculating the logarithm of actual weight dose deposited, Ln (weight dose deposited), stage 1 was 4.43 (SD 1.18), stage 2 was 5.77 (SD 1.11), and stage 3 was 7.28 (SD 1.54). The higher the stage, the higher the weighted total accumulation was found $(P<0.001)$ (Fig. 1 , Table 3$)$. When the mean weight dose deposited 1000 value was calculated according to the response to treatment, 'complete' had values of 351.18 (SD385.32), while 'delayed' had 1328.92 (SD2607.23), and none had 2532.48 (SD6604.07). The higher weighted total accumulation was found as the response to therapy was delayed or none (Fig. 1, Table 3) $(P<0.05)$. In addition, in MRONJ, weighted dose depositions were found to have a significant effect on $\mathrm{ONJ}$ staging and treatment response, measured by ordinal logistic regression, with $95 \%$ of confidence level $(P<0.05)$ (Table 4).

\section{Discussions}

Oral BPs are agents commonly used for osteoporosis and osteopenia, while intravenous BPs may also be used to manage cancer-related conditions, especially for bone metastases of a breast, lung, or prostate primary solid cancer, or lytic lesions developed in patients with multiple myeloma [30-35]. Considering the demographic factors, higher prevalence of $\mathrm{ONJ}$ is reported in the female population. This can be explained by the therapeutic indication (breast cancer, osteoporosis) [7].

In this study, female patients were found to account for significantly higher portions than male. Among the underlying diseases, osteoporosis accounted for high 
Table 2 Main characteristics of bisphosphonates (BPs)

\begin{tabular}{|c|c|c|c|c|c|}
\hline Type of BPs & Relative potency & $\begin{array}{l}\text { Average dose } \\
\text { administered (mg) }\end{array}$ & Bone absorption rate & $\begin{array}{l}\text { Average dose deposited } \\
\text { in bone (mg) }\end{array}$ & $\begin{array}{l}\text { Weight dose } \\
\text { deposited/1000 }\end{array}$ \\
\hline \multirow[t]{2}{*}{ Pamidronate } & 100 & 142,750 & $1 \%(\mathrm{PO})$ & 1427.5 & 142.75 \\
\hline & & 300 & $70 \%(\mathrm{IV})$ & 210 & 21 \\
\hline Alendronate & 1000 & 17,633 & $1 \%(\mathrm{PO})$ & 176 & 176 \\
\hline \multirow[t]{2}{*}{ Ibandronate } & 10,000 & 6900 & $1 \%(\mathrm{PO})$ & 69 & 690 \\
\hline & & 51.43 & $70 \%$ (IV) & 36 & 360.01 \\
\hline Risendronate & 20,000 & 9861.25 & $1 \%(\mathrm{PO})$ & 98.61 & 1972.25 \\
\hline Zoledronate & 100,000 & 62.67 & 70\% (IV) & 43.87 & 4386.90 \\
\hline
\end{tabular}

Relative potency, average dose administered, bone absorption rate, average dose deposited in Bone, weight dose deposited/1000 in this study

portions. It can be due to the female with osteoporosis patients being the majority.

Alendronate $\left(F_{0} a m a x^{\circ}\right)$ was found to be the main inducer of oral MRONJ because of its extensive use with other bisphosphonates [36]. Alendronate was most commonly used in this study as well. However, as the use of other bisphosphonates and other drugs gradually increase [37], alendronate will be less blamed for the leading cause of BRONJ associated with oral administration.

Many additional factors have been reported in the literature as being associated with acceleration of the MRONJ $[38,39]$. They include the use of corticosteroids, the presence of concomitant diseases, or conditions such as diabetes mellitus. Therefore, the general medical history and medication of the patients should be considered.

As shown in the definition of term MRONJ, MRONJ is only found in the mandible and maxilla, highlighting their unique nature compared with other parts of the skeleton. The jaws are the only bones in the human body that are in frequent contact with the external environments and are subject to repeated microtrauma through the presence of teeth and the forces of mastication. Moreover, the turnover of alveolar bone is tenfold greater than in the long bones. While BPs can decrease this turnover, the alveolar remodeling still remains to be more frequent when compared with the long bones. MRONJ affects the mandible more often than the maxilla, while both jaws involvement is rare [40]. In our study, mandibles were found to be affected more than maxilla as well.

Local trauma that are caused by tooth extractions, local surgery, or ill-fitting dentures are the most important risk factors, which are being consistently reported throughout the literature [12]. It is probably multifactorial, with infection and trauma to the bone or soft tissue playing important roles [41]. In this study, 61.6\% patients were found to have local risk factor like tooth extraction (44.2\%). Therefore, patients who are at risk of developing MRONJ need to be educated with adverse effects of the medication like BPs and dentist and dental hygienist should guide the patients for good oral hygiene and put efforts to as little oral irritation as possible at the dental field.
Weight dose deposited according to MRONJ Clinical Stage

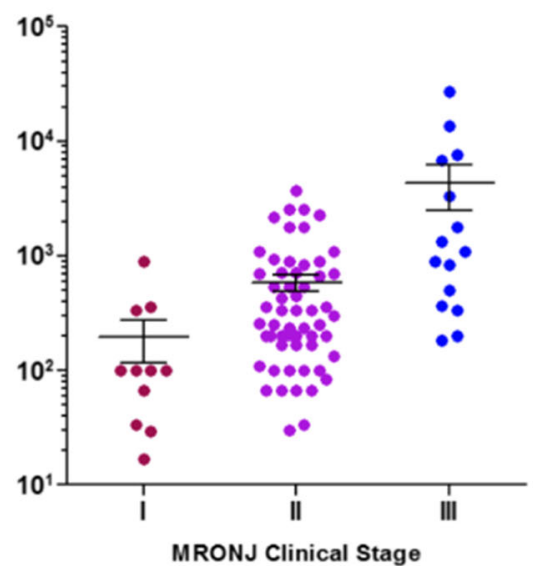

Weight dose deposited according to Treatment Response

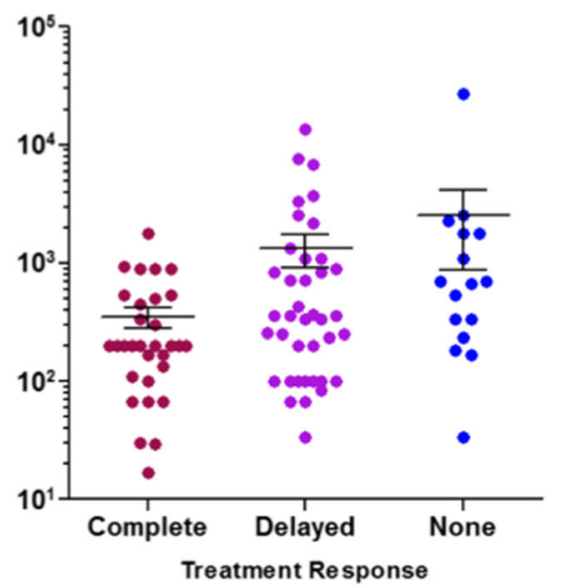

Fig. 1 Weight dose deposited according to MRONJ Clinical Stage and Treatment Response. Actual weight dose deposited were calculated and the values were awarded graph 
Table 3 Weight dose deposited according to MRONJ Clinical Stage and Treatment Response

\begin{tabular}{lll}
\hline \multicolumn{1}{l}{ MRONJ stage } & Ln [weight dose deposited] (SD) & \\
\hline I & $195.15(260.97)$ & $4.63(1.18)$ \\
II & $589.82(746.43)$ & $5.77(1.11)$ \\
III & $4379.89(7317.72)$ & $7.28(1.54)$ \\
Treatment response & & \\
Complete & $351.18(385.32)$ & \\
Delayed & $1328.92(2607.23)$ & \\
None & $2532.48(6604.07)$ &
\end{tabular}

ANCOVA adjusted age, sex MRONJ site, medical comorbidities

Results are shown as mean (SD)

Values of the weight dose deposited was applied logarithm for normal distribution

The higher the stage, the higher the weighted total accumulation was found $(P<0.001)$

Higher weighted total accumulation was found as the response to therapy was delayed or none $(P<0.05)$

Previous studies have shown that the longer the time of exposure to the drug, the greater the likelihood of being affected by MRONJ. Thus, protocols for dental procedures have been reported in patients taking BPs, taking into account the MRONJ risk associated with the duration of drug use [42, 43]. In this study, weighted total accumulation was found to be higher in patients with higher MRONJ clinical stage from stage 1 to stage 3 . Also, when treated according to the MRONJ treatment protocol, the higher the patient's weighted total accumulation, the more delayed the response to treatment. It is suggested that in a pharmaco-pathologic view, the amount of the drug accumulated in the bone due to the average administered dose and the absorption rate of the drug, and relative

Table 4 Weight dose deposited according to MRONJ Clinical Stage and Treatment Response

\begin{tabular}{|c|c|c|c|c|}
\hline & Estimates (SE) & $95 \%$ & $\mathrm{Cl}$ & Significance \\
\hline \multicolumn{5}{|c|}{ Weight dose deposited according to MRONJ Clinical Stage } \\
\hline Ln [weighted dose] & $1.113(0.247)$ & 0.63 & 1.60 & $<0.001$ \\
\hline Age & $-0.043(0.030)$ & -0.10 & 0.02 & $>0.05$ \\
\hline Sex & $-1.033(1.168)$ & -3.32 & 1.23 & $>0.05$ \\
\hline MRONJ site & $1.635(1.344)$ & -1.00 & 4.27 & $>0.05$ \\
\hline Medical comorbidity & $0.089(0.539)$ & -0.97 & 1.15 & $>0.05$ \\
\hline ONJ stage & $5.921(2.898)$ & 0.24 & 11.60 & $<0.05$ \\
\hline \multicolumn{5}{|c|}{ Weight dose deposited according to treatment response } \\
\hline Ln [weighted dose] & $0.443(0.160)$ & 0.13 & 0.76 & $<0.05$ \\
\hline Age & $0.012(0.023)$ & -0.03 & 0.06 & $>0.05$ \\
\hline Sex & $0.237(0.918)$ & -1.56 & 2.04 & $>0.05$ \\
\hline MRONJ site & $-0.917(1.135)$ & -3.14 & 1.31 & $>0.05$ \\
\hline Medical comorbidity & $0.476(0.440)$ & -0.39 & 1.34 & $>0.05$ \\
\hline Tx. response & $4.757(2.354)$ & 0.14 & 9.37 & $<0.05$ \\
\hline
\end{tabular}

Ordinal logistic regression adjusted age, sex MRONJ site, medical comorbidities

Weighted dose depositions were found to have a significant effect on ONJ staging and treatment response, measured by ordinal logistic regression, with $95 \%$ of confidence level $(P<0.05)$ potency of the drug, will be more important than the absolute period of exposure to the drug.

Since 2003, when the adverse effects that bisphosphonates administration on the jaw was recognized, numerous evidence-based case reports have been published in the international literature [44-46] .Zoledronic acid is, by far, the foremost intravenous drug associated with osteonecrosis [47, 48]. Zoledronic acid, administered intravenously over intraorally, has a high accumulation in bone and a relatively high relative potency [27]. The larger the accumulation of the drug in the bone and the greater the relative potency, the larger the weight dose deposited. As found in this study, when administered intravenously, weight dose deposited dose of zoledronate is about 25 times as much as that of the zoledronate when given intraorally.

Physicians believe the benefit of BPs and other drugs used for anti-resorptive and anti-angiogenic therapies outweighs the risk of development of MRONJ in the settings of both osteoporosis and oncology [49, 50]. However, since the risks of ONJ may increase with the amount accumulated in the bone and the relative potency increase, physicians should consider the likelihood and risk of MRONJ when selecting and prescribing the medications in osteoporosis or oncology.

There are still controversies on the benefit of temporary drug holidays with bisphosphonates or other drugs inducing MRONJ in patients who are scheduled to receive invasive dental procedures. The increased risk of pathologic fracture during drug holidays [51] must be balanced with the reduced risk development of MRONJ for individual cases and should be discussed in a multidisciplinary manner.

\section{Conclusion}

Cumulative dose of bisphosphonates deposited in hard tissue is significantly associated with clinical staging and treatment response. Before initiating dental procedures, 
dentists need to evaluate the medical history and reassess the risk of MRONJ proactively. Especially, the medical history of a patient should be gone through for doses used, route of administration, and exposure duration to bisphosphonate or other agents that may increase the risks of MRONJ.

\section{Abbreviations}

AAOMS: American Association of Oral and Maxillofacial Surgeons; BPs: Bisphosphonates; BRONJ: Bisphosphonate-related osteonecrosis of the jaw; CVD: Cardiovascular disease; DM: Diabetes mellitus; ESRD: End-stage renal disease; HTN: Hypertension; MRONJ: Medication-related osteonecrosis of the jaw; ONJ: Osteonecrosis of the jaw; SD: Standard deviation

\section{Acknowledgements}

Not applicable.

\section{Funding}

This research was supported by the Basic Science Research Program through the National Research Foundation of Korea (NRF) funded by the Ministry of Science, ICT \& Future Planning (2016R1C1B2006270).

\section{Availability of data and materials}

Not applicable.

\section{Authors' contributions}

SHJ analyzed and interpreted the patient data. KJW performed. KSJ was a major contributor in writing the manuscript. All authors read and approved the final manuscript.

\section{Ethics approval and consent to participate}

This study was exempted from IRB approval because of study for retrospective anonymous data.

\section{Consent for publication}

Not applicable.

\section{Competing interests}

The authors declare that they have no competing interests.

Received: 11 June 2019 Accepted: 24 June 2019

Published online: 23 July 2019

\section{References}

1. Marx RE (2003) Pamidronate (Aredia) and zoledronate (Zometa) induced avascular necrosis of the jaw: a growing epidemic. J Oral Maxillofac Surg 61:1115-1117

2. Kulkarni R, Cymerman J, Pick A (2014) Antiresorptive related osteonecrosis of the jaw bone (ARONJ); a single maxillofacial unit case series and analysis. Br J Oral Maxillofac Surg 52:74-82

3. Ruggiero SL, Dodson TB, Fantasia J (2014) American Association of Oral and Maxillofacial Surgeons position paper on medication-related osteonecrosisi of the jaw-2014 update. J Oral Maxillofac Surg 72:1938-1956

4. Major P, Lorholary A (2001) Zoledronic acid is superior to pamidronate in the treatment of hypercalcemia of malignancy; a pooled analysis of two randomized, controlled clinical trials. J Clin Oncol 19(2):558-567

5. Hillner BE, Ingle JN, Chlebowski RT, Gralow J, Yee GC, Janjan NA et al (2003) American Society of Clinical Oncology 2003 update on the role of bisphosphonates and bone health issues in women with breast cancer. J Clin Oncol 21(21):4042-4047

6. Saad F, Gleason DM, Murray R, Tchekmedyian S, Venner P, Lacombe L et al (2002) A randomized, placebo-controlled trial of zoledronic acid in patients with hormone-refractory metastatic prostate carcinoma. J Natl Cancer Inst 94(19):1458-1468

7. Saad F, Gleason DM, Murray R, Tchekmedyian S, Venner P, Lacombe L, Chin JL, Vinholes JJ, Goas JA, Zheng M, Zoledronic acid prostate cancer study group (2004) Long-term efficacy of zoledronic acid for the prevention of skeletal complications in patients with metastatic hormone-refractory prostate cancer. J Natl Cancer Inst 96(11):879-882
8. Khan AA, Morrison A, Hanley DA (2015) Diagnosis and management of osteonecrosis of the jaw: a systemic review and international consensus. J Bone Miner Res 30:3-23

9. de Boissieu P, Knangaratnam L, Mahmoudi R, Morel A, Drame M, Trenque T (2017) Adjudication of osteonecrosis of the jaw in phaselll randerminzed controlled trials of denosumab: a systematic review. Eur J Clin Pharmacol 73:517-523

10. Khan AA, Morrison A, Kendler DL (2017) Case-based review of osteonecrosis of the jaw(ONJ) and application of the international recommendations for management from the international task force on ONJ. J Clin Densitom 20:8-24

11. Ruggiero SL, Dodson TB, Fantasia J (2007) American Association of Oral and Maxillofacial Surgeons position paper on bisphosphonate-related osteonecrosis of the jaw. Advisory task force on bisphosphonate-related osteonecrosis of the jaws. J Oral Maxillofac Surg 65:369-376

12. Aghaloo T, Goodday R, Mehrotra T (2009) American Association of Oral and Maxillofacial Surgeons position paper on bisphosphonate-related osteonecrosis of the jaw 2009 update. Aust Endod J 35:119-130

13. Silverman SL, Landesberg R (2009) Osteonecrosis of the jaw and the role of bisphosphonates: a critical review. Am J of Med 122:33-45

14. Mavrokokki T, Cheong A, Stein B, Goss A (2007) Nature and frequency of bisphosphonate-associated osteonecrosis of the jaws in Australia. J Oral Maxillofac Surg 65:415-423

15. Vahtsevanos K, Kyrgidis A, Verrou E, Katodritou E, Triaridis S, Andreadis CG (2009) Longitudinal cohort study of risk factors in cancer patients of bisphosphonate-related osteonecrosis of the jaw. J Clin Oncol 27:5356-5362

16. Filleulo CE, Saussez E (2010) Bisphosphonate-induced osteonecrosis of the jaw: a review of 2400 patient cases. J Cancer Res Clin Oncol 136: 1117-1124

17. Favia G, Pilolli GP, Maiorano E (2009) Osteonecrosis of the jaw correlated to bisphosphonate therapy in non-oncologic patients: clinicopathological features of 24 patients. J Rheumatol 36:2780-2787

18. Rodan GA, Fleisch HS (1996) Bisphosphonates: mechanisms of action. J Clin Invest 97:2692-2699

19. Rosen LS, Gordon D, Tchekmedyian NS, Yanagihara R, Hirsh V. Krzakowski M et al (2004) Long-term efficacy and and safety of zoledronic acid in the treatment of skeletal metastases in patients with nonsmall cell lung carcinoma and metastases in patients with nonsmall cell lung carcinoma and other solid tumors: a randomized phase III, double-blind, placebocontrolled trial. Cancer 100(12):2613-2622

20. Benrenson JR, Hillner BE, Kyle RA, Anderson K, Lipton A, Yee GC et al (2002) American Society of Clinical Oncology clinical practice guidelines: the role of bisphosphonates in multiple myeloma. J Clin Oncol 20(17):3719-3736

21. Balica NC, Peonaru M, Stefanescu EH, Boia ER, Cl C, Baderca F et al (2016) Anterior commissure laryngeal neoplasm endoscopic management. Romanian J Morphol Embryol 57(2):715-718

22. Sarau CA, Poenaru M, Balica NC, Baderca F (2017) Rare sinonasal lesions. Romanian J Morphol Embryol 58(4):1541-1547

23. Balica NC, Poenary M, Cl D, Baderca F, Preda MA, lovan VC et al (2018) The management of the oropharyngeal anterior wall cancer. Romanian J Morphol Embryol 59(1):113-119

24. Jianu DC, Jianu SN, Dan TF, Motoc AG, Poenaru M (2016) Pulsatile tinnitus caused by a dilated left petrosquamosal sinus. Romanian J Morphol Embryol 57(1):319-322

25. Sarau CA, Lighezan DF, Doros IC (2015) The involvement of upper airway in Wigener's granulomatosis-about four cases. Romanian J Morphol Embryol 56(2):613-618

26. Marin KC, Berdich-kun KN, Gentil F, Parente M, Natal RJ, Marin HA et al (2014) Application of a finite element model in the diagnosis process of middle ear pathologies. Romanian J Morphol Embryol 55(4):1511-1514

27. Kimmel DB (2007) Mechanism of actions, pharmacokinetic and pharmacodynamic profile, and clinical applications of nitrogen containing bisphosphonates. JCLI 86:1022-1033

28. Ruggiero SL, Fantasia J, Carlson E (2006) Bisphosphonate-related osteonecrosis of the jaw: background and guidelines for diagnosis, staging and management. Oral Surg Oral Med Oral Pathol Oral Radiol Endod 102:433-441

29. Alejandro P. Luis J, Lorena G, Luis GC, Lucia GM, Tommaso C et al (2015) Epidemiology, pharmacology and clinical characterization of 
bisphosphonate-related osteonecrosis of the jaw. A retrospective study of 70 cases. Acta Otorrinolaringol Esp 66(3):139-147

30. Ruggiero SL, Mehrotra B, Rosenberg TJ, Engroff SL (2004) Osteonecrosis of the jaws associated with the use of bisphosphonates: a review of 63 cases. J Oral Maxillofac Surg 62(5):527-534

31. Reid IR, Bolland MJ, Grey AB (2007) Bisphosphonate-associated osteonecrosis of the jaw caused by soft tissue toxicity. Bone 41(3):318-320

32. Bamias A, Kastritis E, Bamia C, Moulopoulos LA, Melakopoulos I, Bozas G et al (2005) Osteonecrosis of the jaw in cancer after treatment with bisphosphonates: incidence and risk factors. J Clin Oncol 23(34):8580-8587

33. Bi Y, Gao Y, Ehirchiou D, Cao C, Kikuiri T, Le A et al (2010) Bisphosphonates cause osteonecrosis of the jaw like disease in mice. Am J Pathol 177(1):280-290

34. Hokugo A, Christensen R, Chung EM, Sung EC, Felsenfeld AL, Sayre JW et al (2010) Increased prevalence of bisphosphonate-related osteonecrosis of the jaw with vitamin D deficiency in rats. J Bone Miner Res 25(6):1337-1349

35. Mortensen M, Lawson W, Montazem A (2007) Osteonecrosis of the jaw associated with bisphosphonate use: presentation of seven cases and literature review. Laryngoscope 117(1):30-34

36. Lo JC, O'Ryan FS, Gordon NP, Yang J, Hul RL (2010) Prevalence of osteonecrosis of the jaw in patients with oral bisphosphonate exposure. J Oral Maxillofac Surg 68:243-253

37. Ruggiero SL, Mehrotra B (2004) Ten years of alendronate treatment for osteopososis in postmenopausal women. New Engl J Med 351:190-198

38. Malden N, Lopes V (2002) An epidemiological study of alendronaterelated osteonecrosis of the jaws. A case series from the south-east of Scotland with attention given to case definition and prevalence. J Bone Miner Metab 30(2):171-182

39. Grbic JT, Black DM, Lyles KW, Reid DM, Orwoll E, McClung M et al (2010) The incidence of osteonecrosis of the jaw in patients receiving 5 milligrams of zoledronic acid: data from the health outcomes and reduced incidence with zoledronic acid once yearly clinical trials program. J Am Dent Assoc 141(11):1365-1370

40. Francesco B (2013) Bisphosphonate-related osteonecrosis of the jaws (BRONJ). Oral Patol Oral Cir Buccal 18(5):752-758

41. Saussez S, Javadian R, Hupin C, Magremanne M, Chantrain G (2009) Bisphosphonate-related osteonecrosis of the jaw and its associated risk factors: a Belgian case series. Laryngoscope 119:323-329

42. Wood J, Bonjean K, Ruetz S, Bellahcène A, Devy L, Foidart JM et al (2002) Novel antiangiogenic effects of the bisphosphonate compound zoledronic acid. J Pharmacol Exp Ther 302(3):1055-1061

43. Vescovi P, Merigo E, Meleti M, Manfredi M, Guidotti R, Nammour S (2007) Bisphosphonates-related osteonecrosis of the jaws: a concise review of the literature and a report of a single-centre experience with 151 patients. J Oral Pathol Med 41(3):214-221

44. Fedele S, Porter SR, D'Aiuto F, Aljohani S, Vescovi P (2010) Nonexposed variant of bisphosphonate-associated osteonecrosis of the jaw: a case series. Am J Med 123:1060-1064

45. Mawardi H, Treister N, Richardson P, Anderson K, Munshi N (2009) Sinus tracts an early sign of bisphosphonateassociated osteonecrosis of the jaws. J Oral Maxillofac Surg 67:593-601

46. Bagan JV, Jimenez Y, Diaz JM, Murillo J, Sanchis JM (2009) Osteonecrosis of the jaws in intravenous bisphosphonate use: proposal for a modification of the clinical classification. Oral Oncol 45:645-646

47. Ficarra G, Beninati F (2007) Bisphosphonate-related osteonecrosis of the jaw; the point of view of the oral pathologist. Clin Cases Miner Bone Metab 4:53-57

48. Otto S, Abu-ld MH, Fedele S, Warnke PH, Becker ST, Kolk A (2011) Osteoporosis and bisphosphonates-related osteonecrosis of the jaw; not just a sporadic coincidence; a muli-centre study. J Craniomaxillofac Surg 39:272-277

49. Neville B, Damm DD, Allen C, Chi A (2016) Oral and maxillofacila pathology. Elsevier, Ed 4, St. Louis, Amsterdam

50. Hellstein JW (2011) Managing the care of patients receiving antiresorptive therapy for prevention-related osteonecrosis: executive summary of recommendations from the American Dental Association Council on Scientific Affairs. J Am Dent Assoc 142:1243-1251

51. Ramaglia L (2018) Stage-specific therapeutic strategies of medication related osteonecrosis of the jaw; a systematic review and meta-analysis of the drug suspension protocol. Clin Oral Investing 22:597-615

\section{Publisher's Note}

Springer Nature remains neutral with regard to jurisdictional claims in published maps and institutional affiliations.

\section{Submit your manuscript to a SpringerOpen ${ }^{\circ}$ journal and benefit from:}

- Convenient online submission

- Rigorous peer review

- Open access: articles freely available online

- High visibility within the field

- Retaining the copyright to your article

Submit your next manuscript at $\boldsymbol{\nabla}$ springeropen.com 